\title{
Modeling and Simulation of Phase Change Material Wallboards to Improve Indoor Thermal Comfort: A Case Study of Residential Buildings of urban village in Guangzhou
}

\author{
Kunlun $\mathrm{Li}^{1, *}$ \\ ${ }^{1}$ College of National defense engineering, Army Engineering University of PLA, 210000, Nanjing, Jiangsu province, PR China
}

\begin{abstract}
Phase change materials can not only save thermal storage, but also improve residential thermal comfort. In this paper, the finite element software COMSOL is used to simulate the effect of phase change material wallboards on the improvement of residential comfort in the urban village of Guangzhou, China. The results clearly show that the use of phase change material wallboards has a positive influence on the indoor thermal comfort of the urban village.
\end{abstract}

\section{Introduction}

The urban village, which can be regarded as shantytown, with a high building density, a large population, and a high plot ratio, is the typical product of rapid urbanization in China. Guangzhou is a typical city in south China, and residences of urban villages in Guangzhou, with simple configurations, lack of direct sunlight environment and hot and humid climate, is a good case to study on the approach to improve indoor thermal comfort for enhancing human comfort level. Because indoor thermal performance is important to thermal comfort, the indoor thermal performance of a model was studied in this research [1].

Phase change materials (PCMs) can store and release thermal energy as latent heat during the change in phase, which is supposed to contribute to the passive building design. And the wallboards are cheap and because of their low price, wallboards are very suitable for PCM encapsulation. Therefore, PCM wallboard was applied in this research for improving thermal energy storage so thermal comfort will be enhanced.

In order to evaluate the thermal influence of this PCM wallboard on indoor thermal performance, a modeling building based on Residence A in urban village of Guangzhou [1] was presented in this paper, which was first equipped with and then without PCM wallboards. Because it has the biggest change in temperature in April and the highest temperature in July, indoor temperature in these two months is tested. To perform the numerical simulation, a finite element analysis software called COMSOL was adopted.

This paper focuses on the indoor thermal performance of the modeling building. It makes a comparison of the indoor thermal performance of different areas of the model between the case with PCM and the case without PCM in April and July. Finally, it presents the simulation results and conclusions.

\section{COMSOL and process of simulation}

\section{$2.1 \mathrm{COMSOL}$}

COMSOL is a general-purpose simulation software for modeling designs, devices, and processes in all fields of engineering, manufacturing, and scientific research. It can be used on its own or expanded by any combination of add-on modules for simulating electromagnetics, structural mechanics, acoustics, fluid flow, heat transfer, and chemical engineering.

\subsection{Process of simulation in COMSOL}

CAD import, fluid flow and heat transfer modules are utilized in the simulation. Firstly, a model designed with CAD is input into the simulation. Then the initial conditions are built up and properties of arrangements are imported according to fluid flow and heat transfer modules. Finally, run the process and get the results based on the model partitioned by finite element mesh.

\section{The studied model}

\subsection{Initial conditions}

\footnotetext{
* Corresponding author: kunlun_li@foxmail.com
} 


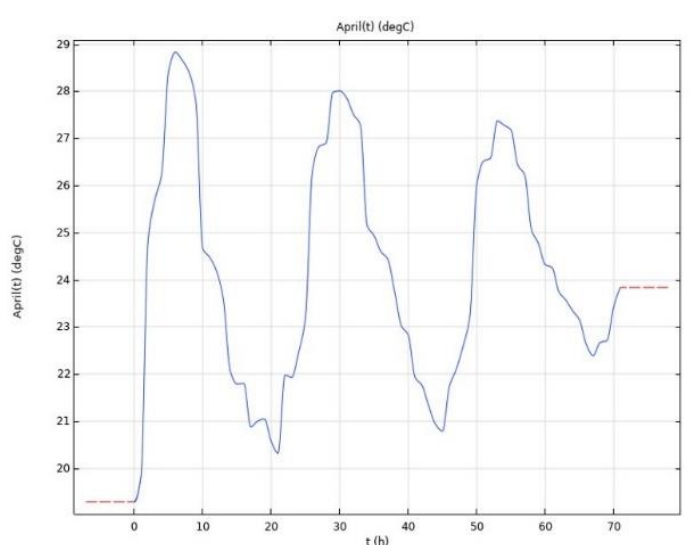

(a)

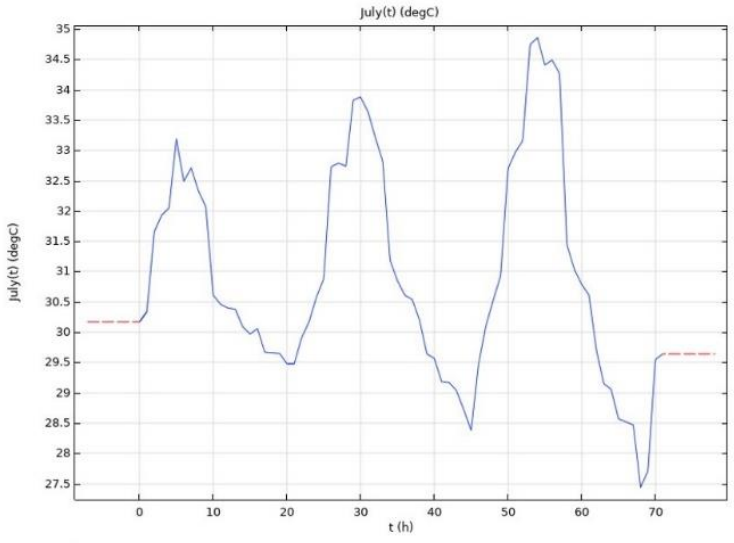

(b)

Fig.1. Three days of ambient temperature on April 2020(a) and July 2020(b)[2]

Since the temperature changing range in Guangzhou is the largest in April, and the temperature in Guangzhou is the highest in July, these severely damage indoor thermal comfort. Therefore, this study simulates the ambient temperature of these two months, namely the temperature in July for 3 days and the temperature in April for 3 days, as shown in Figure 1. And the initial temperature of the tested model, including indoor temperature and arrangements temperature, is chosen as $26^{\circ} \mathrm{C}$. In this study, the model is regarded as closed, and no ventilation is set up in the simulation. Residences in urban village usually lack solar illumination, thus no sunlight is considered in the simulation.

\subsection{Configurations of the model}

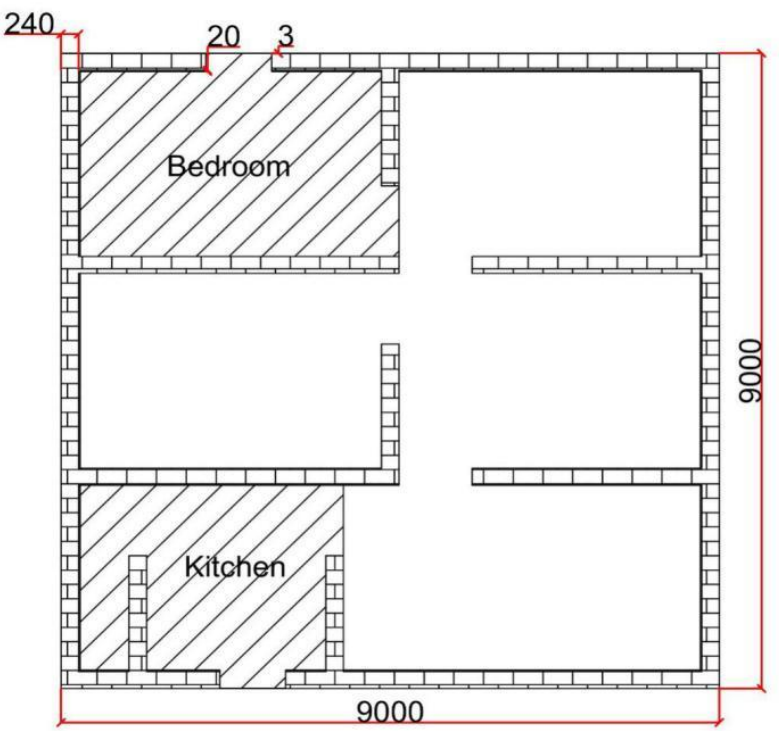

Fig.2. The simulated model (Unit: $\mathrm{mm}$ )
As depicted in Figure 2, a $9 \mathrm{~cm}^{*} 9 \mathrm{~cm}$ square is studied. It consists of two windows on the walls of the bedroom and kitchen, $240 \mathrm{~mm}$ wide external walls and $20 \mathrm{~mm}$ wide PCM wallboards on the inner surface of an external wall. The size and shape of the model are transformed from Residence A $[1]$.

\subsection{The properties of arrangements}

The window is considered to be simplified as a $3 \mathrm{~mm}$ single-layer glass for the convenience of modeling.[3] Because the thickness of PCMs is a parameter affecting the thermal performance of PCM wallboard and paper shows that no obvious improvement of indoor thermal performance when the thickness of PCMs is greater than 20mm. [4] So the thickness of the PCM wallboard is set up to be $20 \mathrm{~mm}$ for a highly cost-effective.

The material of the external wall is brick and its properties are from the common settings of COMSOL. And the properties of PCM wallboard are provided by Hubei thermal new energy technology co., ltd., as presented in Table 1. Window and wall properties are illustrated in Table 2 . 
Table 1. Properties of PCM wallboard

\begin{tabular}{|c|c|c|}
\hline Parameter & Value & Unit \\
\hline Thermal conductivity & 0.173 & $\mathrm{~W} /(\mathrm{m} \cdot \mathrm{K})$ \\
\hline Density & 1050 & $\mathrm{~kg} / \mathrm{m}^{3}$ \\
\hline Specific heat capacity & 120 & $\mathrm{~J} /(\mathrm{kg} \cdot \mathrm{K})$ \\
\hline Latent heat & 120 & $\mathrm{~kJ} / \mathrm{kg}$ \\
\hline Phase change temperature & 26 & ${ }^{\circ} \mathrm{C}$ \\
\hline Thickness & 20 & $\mathrm{~mm}$ \\
\hline
\end{tabular}

Table 2. Characteristics of wall and window

\begin{tabular}{|c|c|c|}
\hline Elements & Composition & Remark(s) \\
\hline \multirow{2}{*}{ Wall } & & Density $=2000 \mathrm{~kg} / \mathrm{m}^{3}$ \\
& & $\begin{array}{c}\text { Specific heat capacity: } \\
\mathrm{Cp}=900 \mathrm{~J} /(\mathrm{kg} \cdot \mathrm{K})\end{array}$ \\
& $240 \mathrm{~mm}$ thick brick & $\begin{array}{c}\text { Thermal conductivity: } \\
\mathrm{k}=0.5 \mathrm{~W} /(\mathrm{m} \cdot \mathrm{K})\end{array}$ \\
& & Density $=1050 \mathrm{~kg} / \mathrm{m}^{3}$ \\
& & Specific heat capacity: \\
& & $\mathrm{Cp}=897.4 \mathrm{~J} /(\mathrm{kg} \cdot \mathrm{K})$ \\
& & \\
& $3 \mathrm{~mm}$ thick glass & Thermal conductivity: \\
& & $\mathrm{k}=0.173 \mathrm{~W} /(\mathrm{m} \cdot \mathrm{K})$ \\
& &
\end{tabular}

\section{Simulations with COMSOL}

In this part, initial conditions and properties of arrangements presented in Part 3 are applied in Fluid and heat transfer

modules of COMSOL. Then the results of simulation and relevant discussions are shown below.

\subsection{The results of overall thermal performance}

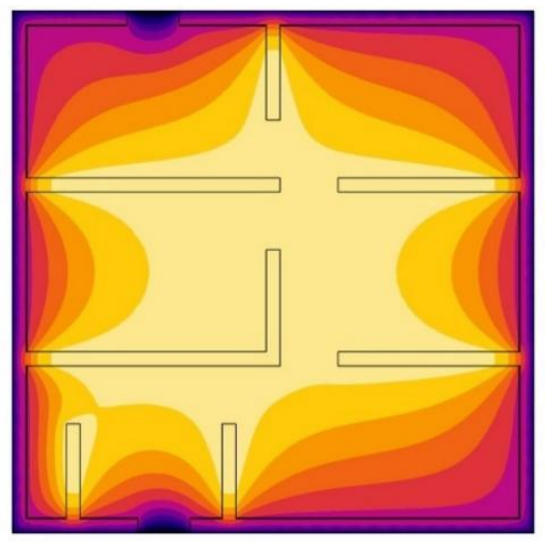

(a)

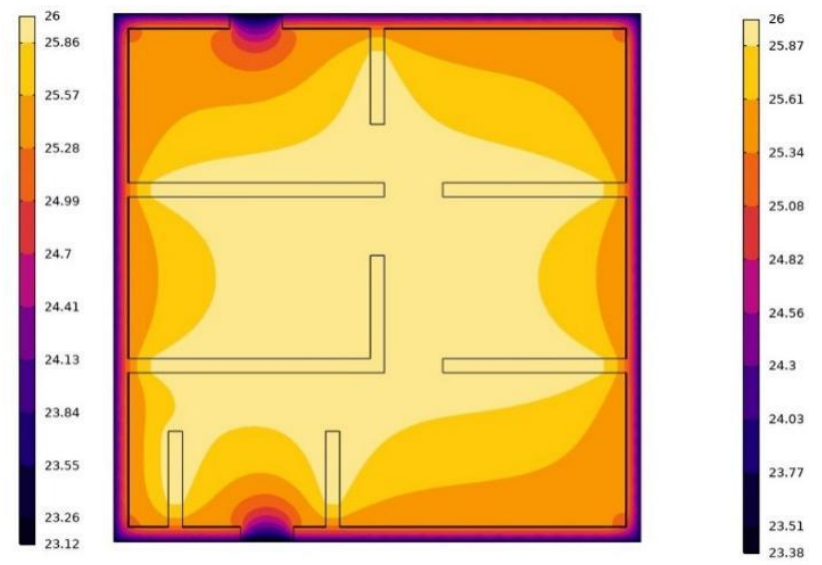

(b)

Fig.3. Overall final temperature isolines of the model without $\mathrm{PCM}(\mathrm{a})$ and the model with $\mathrm{PCM}(\mathrm{b})$ in April

Figure 3 illustrates the final temperature isolines of two different cases. Similar performances and different results can be observed in Figure 3. Both graphs show that the wavy isotherms spread from corners of external walls and windows, meaning that the heat is largely transferred from windows and the inner surface of corners of the external wall. These components are called "thermal bridges", which can cause large heat loss, moisture problems and high energy demand.[5] However, no obvious thermal transmission in internal wall can be observed in both graphs, implying that there is no need to install PCM wallboards on internal wall. As for the different results, comparing to Graph(a) which shows a large cascade heat loss in the model without PCM, Graph(b) presents that a better thermal storage and a more stable thermal performance in the case with PCM wallboards. Also, the proportion of deep colors in Graph(a) is higher than that in Graph(b), showing that most of the areas in the case without PCM have a lower temperature less than $25^{\circ} \mathrm{C}$ while it is close to $26^{\circ} \mathrm{C}$ in most areas in the case with PCM. 


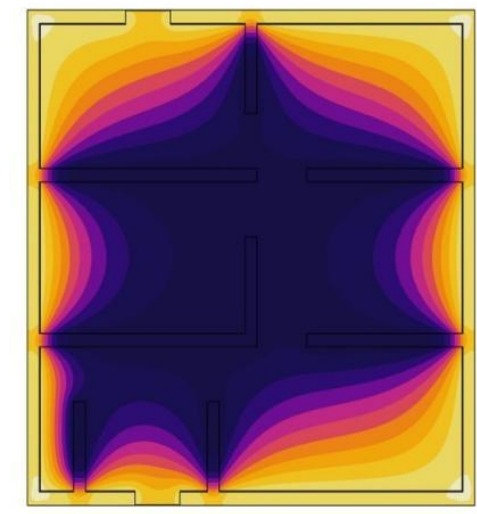

(a)
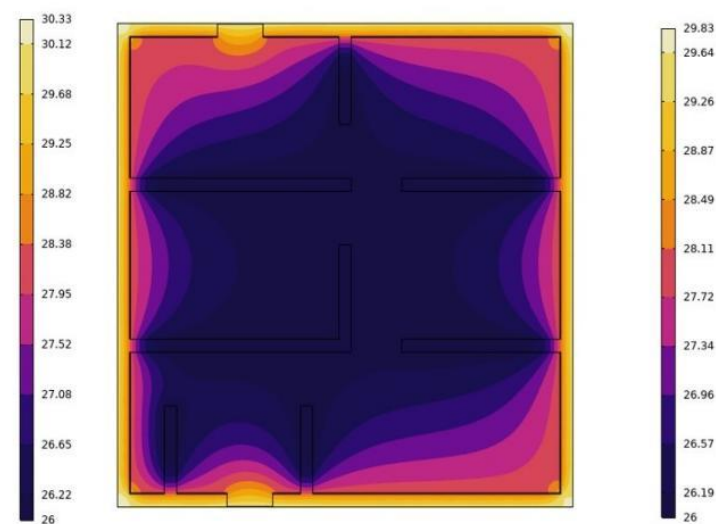

(b)

Fig.4. Overall final temperature isolines of the model without $\mathrm{PCM}(\mathrm{a})$ and the model with $\mathrm{PCM}(\mathrm{b})$ in July

Some similar patterns of thermal performance are shown in Figure 4 as Figure 3 presents. For instance, windows and corners of external walls are thermal bridges and almost no transmission of heat can be found in internal wall. However, due to different ambient temperatures, there are various thermal performances as illustrated in Figure 4. Under the condition of constant high temperature outdoors, a large proportion of areas have an indoor temperature that over $28^{\circ} \mathrm{C}$ as depicted in Graph(a), especially in the rooms with windows and corners of external walls. In comparison, there are more proportion of deep colors in Graph(b), meaning that it is close to $26^{\circ} \mathrm{C}$ in the case with PCM.

To summarize, the PCM wallboards installed on the inner surface of external wall can keep the indoor temperature around $26^{\circ} \mathrm{C}$ and finally improve the indoor thermal comfort of urban villages in Guangzhou in April and July.

\subsection{The results and discussions of temperature change}

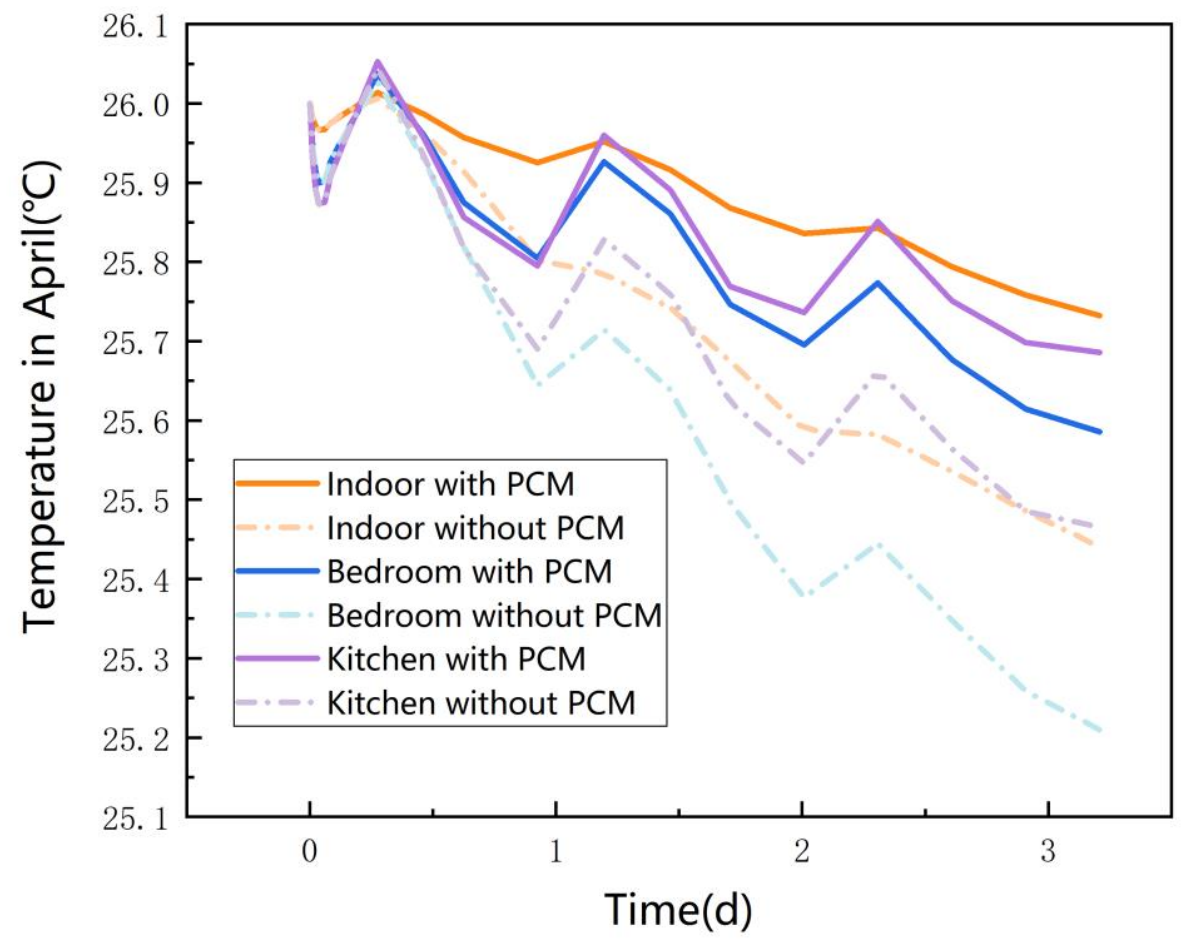

Fig.5. Temperature change of different areas of the model in April

As presented in Figure 5, a downward trend can be observed on the whole while there are some ups and downs during the period. This is because the outdoor temperature is lower than $26^{\circ} \mathrm{C}$ for about 20 hours per day and it changes a lot during these 3 days. In order to take the influence of thermal bridges into consideration, three different areas which are 
kitchen, bedroom and the whole indoor area are studied in this research. For the cases without PCM, the kitchen' $\mathrm{s}$ temperature is close to indoor temperature while the bedroom's temperature has a big difference with indoor temperature.

According to Graph(a) in Figure 3, although there are corners of the external wall and windows in kitchen, an inner wall inside the kitchen blocks the thermal transmission and finally improves the thermal storage of kitchen. This provides evidence for the phenomenon that the kitchen temperature is close to the indoor temperature. However, as there is no inner wall inside the bedroom, thermal transfer in the bedroom leading to a large thermal loss. In Figure 5, solid lines stand for the case with PCM and dotted lines represent the case without PCM. It is clear that ordinates of solid lines remain around $26^{\circ} \mathrm{C}$, but that of dotted lines decrease rapidly from $26^{\circ} \mathrm{C}$ to nearly $25^{\circ} \mathrm{C}$, which shows that when applying PCM wallboards, temperature for different areas can be kept around $26^{\circ} \mathrm{C}$, so the thermal influence of thermal bridges is mitigated.

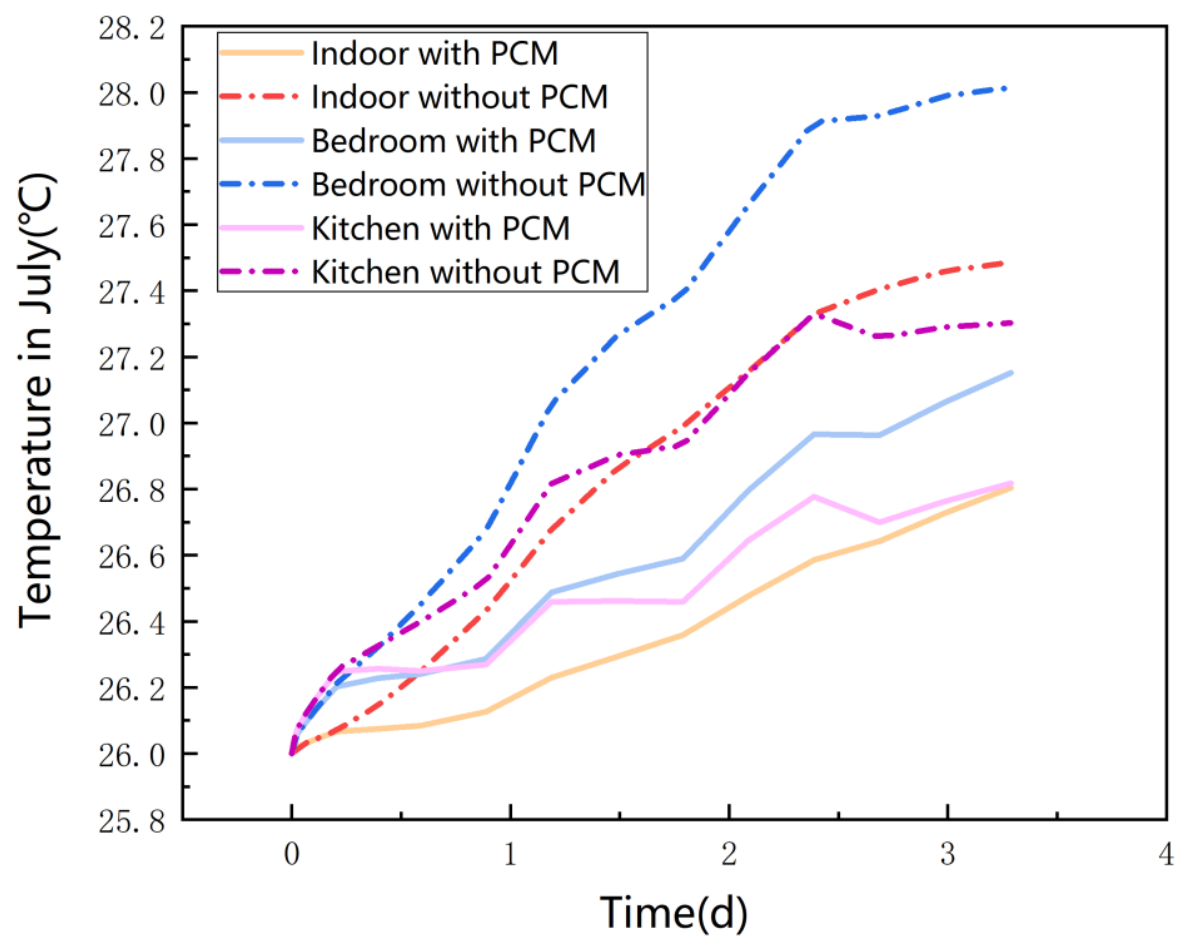

Fig.6. Temperature change of different areas of the model in July

Because the ambient temperature is constantly higher than $26^{\circ} \mathrm{C}$ in July, the indoor temperature for all studied cases increases continuously. Three studied cases and what solid lines and dotted lines stand for in Figure 6 are the same as Figure 5. In Figure 6, bedroom' $\mathrm{s}$ temperature is much higher than that of kitchen and indoor area while kitchen' $\mathrm{s}$ temperature is close to the temperature of indoor area. The reason for this phenomenon is the same as the discussion in Figure 5. The ordinates of solid lines are slightly over than $26^{\circ} \mathrm{C}$ but that of dotted lines increase rapidly from $26^{\circ} \mathrm{C}$ to over $27^{\circ} \mathrm{C}$ or even $28^{\circ} \mathrm{C}$. As the pattern of solid lines represents, even though there exists the influence of thermal bridges, PCM wallboards can still come into effect to improve thermal storage.

In a summary, for the above cases, the temperature can be kept around $26^{\circ} \mathrm{C}$ so thermal comfort can be improved with the installation of PCM wallboards. Even though there exists the influence of thermal bridges, this influence is largely mitigated by PCM wallboards.

\section{Conclusion and future works}

This research utilizes the finite element software, COMSOL, to perform temperature numerical simulations. In fact, the results prove that the PCM wallboard is able to improve the indoor thermal comfort of residences in urban villages in Guangzhou in April and July. In the tested configuration, the temperature changing rate of the PCM building is decreased by about $50 \%$ than that of the non-PCM building, representing better thermal storage and better thermal comfort. The problems of thermal bridges are observed from the results of simulations and these problems are studied and discussed in this research. And the results show that the influence of thermal bridges can be mitigated when applying PCM wallboards. For future works, because moisture and humid problems lead to undermining thermal comfort, especially in cold environments[6], later research should apply the CFD module in simulation to perform the performance of humidity. In addition, although this paper 
regards the model as closed, natural ventilation should be taken into consideration for more specific simulation.

I want to thank Prof. Agarwal Ramesh from Washington University of St. Louis, Xiaofang Wen and Min Han.

\section{References}

1. Zhisheng Li, Jiawen Liao, Xuhong Liu. Indoor Thermal Environmental Testing and Analysis of Residential Homes in The Typical City of Guangzhou, Building Science, 2011, 27 (08): 24-28.

2. ERA5 hourly data on single levels from 1979 to present ( https://cds.climate.copernicus.eu/)

3. Zizhong Dong, Yongguang Xu, Qigao Chen, Yongling Wen. Simplified calculation of window heat transmission coefficients. New building materials, 2002 (09): 40-44.

4. Xu Xu,Yinping Zhang,Kunping Lin,Hongfa Di,Rui Yang. Modeling and simulation on the thermal performance of shape-stabilized phase change material floor used in passive solar buildings[J]. Energy \& Buildings, 2004,37(10).

5. K. Martin,A. Campos-Celador,C. Escudero,I. Gómez,J.M. Sala. Analysis of a thermal bridge in a guarded hot box testing facility[J]. Energy \& Buildings,2012,50.

6. Yufeng Zhang,Jinyong Wang,Huimei Chen,Jun Zhang,Qinglin Meng. Thermal comfort in naturally ventilated buildings in hot-humid area of China[J]. Building and Environment,2010,45(11). 